\title{
Guest Editorial: Cultivating the Vital Element of Youth Mentoring
}

\author{
Belle Liang \\ Boston College \\ Jean Rhodes \\ University of Massachusetts
}

\begin{abstract}
"One looks back with appreciation to the brilliant teachers, but with gratitude to those who touched our human feeling. The curriculum is so much necessary raw material, but warmth is the vital element for the growing plant and for the soul of the child" Jung, 1943, The Gifted Child.
\end{abstract}

In drawing this analogy to plants, Carl Jung emphasized the important role that emotional warmth and a bona fide connection can play in human development. Indeed, decades of research on social developmental processes within families, schools, and communities support this perspective. More recently, the field of cognitive neuroscience has mapped the ways in which relationships interact with the developing brain to shape mental processes and perception-further indicating that virtually every aspect of human development is fundamentally shaped by interpersonal relationships. So, it stands to reason that when close and caring relationships are placed at the center of a youth intervention, as is the case in mentoring programs, the conditions for healthy development are ripe. Close relationships are, in Jung's terms, the vital element of any youth intervention be it a mentoring program, an after school program, or any activity in which youth and adults are working together. When we commit ourselves to supporting high quality bonds, children flourish.

Here is what we know to be true about mentoring. First, not all mentoring relationships are effective and, in some cases, they can do more harm than good. Second, although our knowledge is imperfect, we have a pretty good sense of what is needed for children to thrive in mentoring relationships - most notably authentic, consistent, and enduring ties. Third, high-quality relationships are more likely to unfold in programs that provide adequate planning and support. Indeed, research-

The authors would like to thank Jennifer West, M.A., for her editorial assistance.

Correspondence should be addressed to Dr. Belle Liang, Boston College, 140 Commonwealth Avenue, Chestnut Hill, MA 02467. E-mail: liange@bc.edu ers have identified a range of practices (e.g., sufficient screening, training, contact, structured activities) that are associated with better youth outcomes (Rhodes \& DuBois, 2006). Finally, good mentoring relationships tend to be reciprocal, with mentors deriving a host of benefits through the art of giving of themselves. These benefits include a sense of efficacy and pride that can come from being admired and helpful, as well as insights into their own lives and the lives of youth (Philip \& Hendry, 2000). This mutually beneficial relationship is aptly described by Julie Moir Messervy, a renowned landscaper who observed, "Through gardening, we feel whole as we make our personal work of art upon our land" (1995, p. 19).

\section{On Mentoring and Perennials}

Since the goal of mentoring is the establishment of an enduring relationship with lasting benefits, a mentoring relationship is more like a perennial than an annual. With this in mind, we draw on the wisdom of perennial gardeners to set forth six principles of mentoring - akin to preparing the soil, seeding, weeding, feeding, persevering, and evaluating for the next growing cycle as set forth in Strauss' (2006) The Gardening Analogy.

Lesson One: Prepare the soil- "As with most gardening projects, planning and preparation is best begun well ahead of planting time" (Strauss, 2006, p. 1).

In mentoring, preparing the soil involves prematch preparation and training for volunteers, as well as for youth. Pre-match preparation may start with early identification of individuals who are not a good fit for mentoring work. That is, close, effective mentoring relationships seem to be facilitated when adults possess skills and attributes including: prior experience in helping roles or occupations (DuBois, Holloway, Valentine, \& Cooper, 2002), an ability to demonstrate appreciation of salient socioeconomic and cultural influences in the youth's life (Hirsch, 2005), and a sense of efficacy 
in mentoring young people (DuBois, Neville, Parra, \& Pugh-Lilly, 2002; Hirsch, 2005; Karcher, Nakkula, \& Harris, 2005; Parra, DuBois, Neville, Pugh-Lilly, \& Povinelli, 2002). The ability to model relevant behaviors, such as skills required for successful job performance (Hamilton \& Hamilton, 2005) and refraining from actions (e.g., substance use) that may encourage youth to adopt unhealthy behaviors (Beam, Gil-Rivas, Greenberger, \& Chen, 2002) appear to be of further benefit.

Besides pre-screening and selection, programs can also act proactively by setting appropriate expectations for the mentoring role, processes, and outcomes. For example, many mentors expect that an immediate bond will develop with their protégés and that the balance of the experiences will be more "fun" than work, or they assume their protége will be grateful for the many sacrifices that the volunteer has made on his or her behalf. Such expectations can lead mentors to feel disappointed, unappreciated, and even exploited, especially early in the relationship. Young people are often brought into a mentor program because they have had unsatisfactory relationships in the past, and they may not know how to engage in a mutually satisfying friendship. Alternatively, adequately conveying to volunteers what they can expect from their protégé, the relationship, and the roles of each partner, as well as the difficulties that they might encounter can prevent some of these disappointments (Lindenberger \& Zackary, 1999). Some practitioners have argued that such "full disclosure" might amount to scaring away potential volunteer recruits and, indeed it would be a mistake to delve into every possible way that a relationship can go awry. Yet, the pendulum has swung too far in the other direction, where, in an effort to recruit more volunteers, many programs overemphasize the enjoyable, social aspects of the endeavor. Despite these messages and expectations emphasizing the "fun" aspects of mentoring, the fact is, volunteers who work on youth development issues have reported other motivations for their involvement, especially the desire to increase their understanding of themselves, others, and the world around them (e.g., "mentoring allows me to gain a new perspective on things," Stukas, Daly, \& Clary, 2006). Ultimately, when the actual experience of mentoring aligns with their motivations or expectations, volunteers are less likely to drop out prematurely.

Lesson Two: Seed-"Plant the seeds and seedlings in the soils that match variations in their conditions" (Strauss, 2006, p. 1).
Finding the right fit between volunteers and youths is critical to the longevity and outcomes of the match. Mentors and youth come with different backgrounds, personalities, expectations, and skill levels; matching and training should take these differences into account. Youth protégés typically represent diverse demographics, including boys and girls who differ by racial and ethnic minority background, socioeconomic status, disability, and religion (Balcazar, Majors, Blanchard, \& Paine, 1991; Blechman, 1992). Although the research does not necessarily indicate that mentors must be matched on these dimensions, studies do show the importance of a basic compatibility between the youth and mentor in their personalities, interests, and expectations or goals for the relationship (Bernier \& Larose, 2005; Madia \& Lutz, 2004). In addition, close emotional connections between youth and mentors appear to be fostered by factors resembling those identified as important in effective therapeutic relationshipsmutual empathy and authenticity (Spencer, 2006) as well as basic compatibility and enjoying each other's company (Spencer \& Rhodes, 2005).

Lesson Three: Weed - "remove weeds and other competitive threats" (Strauss, 2006, p. 1).

Not everything that sprouts in a garden belongs there and, likewise, mentors and their case workers need to be on the lookout for insidious problems that may arise at any point in the match. Vigilance against such negative influences requires reasonable ratios between case workers and mentors, so that case workers are not overwhelmed by the number of cases and are thus able to provide adequate supervision to mentors. Mentoring relationships, like other types of relationships, are constantly at risk for misunderstanding, conflict, and various types of communication breakdowns, particularly in the early, vulnerable stages of the relationship. As Shakespeare observed, "Sweet flowers are slow and weeks make haste." If not handled well, relationship problems can compromise the bond before it has had a chance to take hold. Whatever the source of dissatisfaction or unmet expectation, communication is always critical. Bottom Line: Case workers and mentors need to address problems as they arise so that the problems do not compromise the ability for a strong relationship to take root.

Lesson Four: Feed - "amend the soil and keep plants cared for-pruned, fed, and strong - so that threats can't harm them" (Strauss, 2006, p. 1).

In many mentoring programs, training efforts are uneven and fall largely in the realm of passive approaches (e.g., information packets to mentors) rather than active technical assistance. Furthermore, 
many programs spend minimal time with case management, which often takes the form of monthly perfunctory phone calls or emails. Taken together, these approaches have reduced the burden that is placed on the agency and volunteer in order to facilitate shifts in priorities toward volunteer recruitment, intake, and matching. Yet, research indicates that comprehensive orientation, supervision, consultation, and volunteer staff development, are all critical to promoting growth.

In addition to relationship-building skills, mentors must be trained regarding ethnic and cultural issues as well as developmental issues, and how these intersect with power dynamics that are particularly relevant in mentoring youth. For example, because most youth entering mentoring relationships are still minors and live at home where struggles for autonomy and control prevail, mentors need to attend to the subtle dynamics of the parent-child dyad. Furthermore, because youth are simultaneously undergoing multiple developmental changes in biological, psychological, and social realms, their mentors must have a solid grasp of developmental issues and cultural issues that may shape the needs, values, and perspectives of youth. In addition to these important areas of training and growth, volunteers and youth need adequate contact with supportive individuals who provide encouragement and feedback conducive to establishing strong roots for mentoring relationships.

Lesson Five: Persevere-“Don't give up on a dead plant” (Strauss, 2006, p. 1).

Mentors need to be encouraged to persevere in maintaining the relationship given that most youth mentor relationships take time to evolve and their benefits accrue over time. Even seemingly disinterested protégés or unfruitful relationships may spring up or begin new growth unexpectedly. Thus, mentors should be made aware of research documenting the relatively slow pace of a youth mentor relationship as its most natural course, so that they come to expect a period of early dormancy similar to that described by Edward Payson Roe: "Look at us, said the violets blooming at her feet, all last winter we slept in the seeming death but at the right time God awakened us, and here we are to comfort you" (1876).

Lesson Six: Evaluate - "Watch the garden to see soil changes, to know what plants will continue to flourish and to know what new plants to introduce" (Strauss, 2006, p. 1).

Because it is generally assumed that mentoring benefits young people, programs may be hesitant to spend precious resources on expensive program evaluations. Choosing not to evaluate, however, is shortsighted. Effective program evaluation can provide vital information about a program; this enables informed decisions regarding what is working as well as where resources and efforts might be re-directed. Indeed, not all mentoring programs, or interventions within mentoring programs, are equally beneficial and much is still to be learned about the newer types of mentoring programs (e.g., site-based, group, peer, internet). Moreover, much is to be learned about which aspects of mentoring programs are beneficial and transformative and which are less so.

\section{Final Thoughts}

To be effective, mentors need to tolerate all kinds of uncertainties, to address ethical dilemmas and disappointments as they arise, and to know whom to turn to for consultation and how to work through uncharted territories. Yet, naturalist Frederick Frye Rockwell (1917) provided a useful caveat regarding the limitations of such principles:

"The gardener who imagines that his work can be reduced to a set of rules and formulae, followed and applied according to special days marked on the calendar, is but preparing himself for a double disappointment."

Likewise, although the mentoring guidelines presented here and elsewhere are useful, an individual approach to each youth should be crafted. Guidelines can only touch the surface of the intricacies involved in mentoring someone. They are likely to be most effective when they are used as a framework that leaves room for volunteers' to apply their intuitive wisdom and allow the relationship to grow and thrive in all of its complexity.

\section{References}

Balcazar, F. E., Majors, R., Blanchard, K. A., \& Paine, A. (1991). Teaching minority high school students to recruit helpers to attain personal and educational goals. Journal of Behavioral Education, 1(14), 445-454.

Beam, M. R., Gil-Rivas, V., Greenberger, E., \& Chen, C. (2002). Adolescent problem behavior and depressed mood: Risk and protection within and across social contexts. Journal of Youth and Adolescence, 31, 343-357.

Bernier, A., \& Larose, S. (2005). Academic mentoring in college: The interactive role of student's and mentor's interpersonal dispositions. Research in Higher Education, 46, 29-51.

Blechman, E. A. (1992). Mentors for high-risk minority youth: From effective communication to bicultural competence. Journal of Clinical Child Psychology, 21(2), 160-169.

DuBois, D. L., Holloway, B. E., Valentine, J. C., \& Cooper, H. (2002). Effectiveness of mentoring programs for youth: A metaanalytic review. American Journal of Community Psychology, 30, 157-197. 


\section{CULTIVATING YOUTH MENTORING}

DuBois, D. L., Neville, H. A., Parra, G. R., \& Pugh-Lilly, A. O. (2002). Testing a new model of mentoring. In G. G. Noam (Ed.-in-chief), \& J. E. Rhodes (Eds.). A critical view of youth mentoring. (New Directions for Youth Development: Theory, Research, and Practice, No. 93, pp. 21-57). San Francisco: Jossey-Bass.

Hamilton, M. A., \& Hamilton, S. F. (2005). Work and servicelearning. In D. L. DuBois, \& M. J. Karcher (Eds.), Handbook of youth mentoring (pp. 348-363). Thousand Oaks, CA: Sage.

Hirsch, B. J. (2005). A place to call home: After-school programs for urban youth. Washington, DC: American Psychological Association and New York: Teachers College Press.

Karcher, M. J., Nakkula, M. J., \& Harris, J. T. (2005). Developmental mentoring match characteristics: Correspondence between mentors' and mentees' assessments of relationship quality. Journal of Primary Prevention, 26, 93-110.

Lindenberger, J. G., \& Zachary, L. J. (1999. February). Play 20 auestions to develop a successful mentoring program. Training \& Development, 53(2), 12-14.

Madia, B. P., \& Lutz, C. J. (2004). Perceived similarity, expectation-reality discrepancies, and mentors' expressed intention to remain in Big Brothers/Big Sisters Programs. Journal of Applied Social Psychology, 34, 598-623.

Messervy, J. M. (1995). The Inward Garden. Boston: Little Brown \& Co.

Parra, G. R., DuBois, D. L., Neville, H. A., Pugh-Lilly, A. O., \& Povinelli, N. (2002). Mentoring relationships for youth: Investigation of a process-oriented model. Journal of Community Psychology, 30, 367-388.
Philip, K., \& Hendry, L. (2000). Making sense of mentoring or mentoring making sense? Reflections on the mentoring process by adult mentors with young people. Journal of Community \& Applied Social Psychology, 10, 211-223.

Rhodes, J. E., \& DuBois, D. L. (2006). Understand and facilitating the youth mentoring movement. Social Policy Report, 20(3). Retrieved February 12, 2006, from http:// www.srcd.org/documents/publications/spr/spr20-3.pdf.

Rockwell, F. F. (1917). Around the Year in a Garden. New York: Macmillan Company.

Roe, E. P. (1876). Near to Nature's Heart. New York: Dodd, Mead \& Co.

Spencer, R. (2006). Understanding the mentoring process between adolescents and adults. Youth \& Society, 37, 287-315.

Spencer, R., \& Rhodes, J. E. (2005). A counseling and psychotherapy perspective on mentoring relationships. In D. L. DuBois, \& M. J. Karcher (Eds.), Handbook of youth mentoring (pp. 118-132). Thousand Oaks, CA: Sage.

Strauss, L. (2006). The Gardening Analogy. Retrieved February 2, 2007, from http://www.lizstrauss.com/2006/05/31/ everyones-business/the-gardening-analogy/

Stukas, A. A., Daly, M., \& Clary, E. G. (2006). Lessons from research on volunteering for mobilizing adults to volunteer for positive youth development. In E. G. Clary, \& J. E. Rhodes (Eds.), Mobilizing adults for positive youth development: Strategies for closing the gap between beliefs and behaviors (pp. 65-82). New York, NY: Springer. 